\title{
EFFECT OF ISOKINETIC VERSUS PLYOMETRIC TRAINING ON SHOULDER PROPRIOCEPTION AND EXTERNAL TO INTERNAL ROTATORS STRENGTH RATIO IN SWIMMER CHILDREN
}

\section{Samah Attia El Shemy *1, Kadrya Hosny Battecha ${ }^{2}$.}

${ }^{* 1}$ Assistant Professor, Department of Physical Therapy for Growth and Developmental Disorders in Children and Its Surgery, Faculty of Physical Therapy, Cairo University, Egypt.

${ }^{2}$ Assistant Professor, Department of Basic Science, Faculty of Physical Therapy, Cairo University, Egypt.

\section{ABSTRACT}

Background: Many exercise protocols intended to enhance kinesthetic awareness and muscular performance, however more investigations need to be directed to the restoration of muscular imbalances.

Objective: To compare the impacts of isokinetic training and plyometric training of the rotator cuff muscles on shoulder proprioception and isokinetic strength ratios.

Materials and Methods: Seventy five swimmer boys randomly assigned to three equal-sized groups: control group (A) had no strength training, study group (B) received isokinetic training and study group (C) received plyometric training for the rotator cuff muscles. Pre-post testing measurements included: kinesthetic measurements at $45^{\circ}$ of internal rotation, $45^{\circ}$ external rotation and $75^{\circ}$ external rotation; and concentric external/ internal rotation strength ratios at angular velocities of $60 \% \mathrm{~s}$ and $180 \% \mathrm{~s}$ using a Biodex System 3 isokinetic dynamometer. The test procedure performed before and after the training period of eight weeks.

Results: Both training groups showed pre-posttest significant differences in all measured variables with nonsignificant changes in the control group. When comparing the post-treatment results in both training groups, the isokinetic group showed the most significant improvement in the strength ratio. However, no significant differences in kinesthetic awareness found between both training groups.

Conclusion: Isokinetic strengthening is the most effective strategy of adjusting strength ratios of the rotator cuff muscles. Moreover, both isokinetic and plyometric training enhanced kinesthetic awareness, neither technique was superior.

KEY WORDS: Isokinetic Training, Plyometric Training, Rotator Cuff, Proprioception, Strength Ratio, Swimmers.

Address for correspondence: Dr. Samah Attia El Shemy, PhD, Assistant Professor, Department of Physical Therapy for Growth and Developmental Disorders in Children and Its Surgery, Faculty of Physical Therapy, Cairo University, Egypt. E- Mail: samah_elshemy@yahoo.com

\section{Access this Article online}

Quick Response code

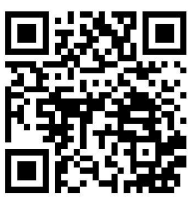

DOI: $10.16965 /$ ijpr.2017.161
International Journal of Physiotherapy and Research

ISSN 2321- 1822

www.ijmhr.org/ijpr.html

Received: 17-04-2017

Peer Review: 18-04-2017

Revised: None
Accepted: $13-05-2017$

Published (P): 11-06-2017
Published (O): 11-06-2017

\section{INTRODUCTION}

Swimming is a peculiar sport in that the shoulders and upper limbs utilized for velocity, at the same time requiring shoulder adaptability and scope of movement for maximal productivity.
This regularly connected with an undesirable increment in joint laxity [1].

Besides; it performed in a liquid medium which offers more imperviousness to movement than air. Ordinarily, swimmers start their extraordi- 
nary preparing at an early age of 8 to 11 years of age. The high recurrence and preparing of swimming can regularly prompt to shoulder overuse injuries, or what is called "swimmer's shoulder" [2].

Proprioception is fundamental to the central sensory system to direct neuromuscular control with a specific end goal to keep up functional joint strength, particularly in the shoulder complex, which depends vigorously on muscular contractions for stability. Subjects with shoulder instability have demonstrated proprioception deficits. It is conceivable that injured or loose ligaments, capsules, and muscles influence proprioception afferent information. Proprioception deficits may bring about impeded neuromuscular control, which could prompt to muscle imbalance and joint instability [3].

Joint position sense (JPS) has recorded as an individual's capacity to reproduce a predetermined joint angle either actively or passively. Both sorts of measurement commonly carried out in the open kinetic chain. Joint position sense testing instruments have extended from the most essential standard goniometer to the more advanced isokinetic dynamometers furnished with their own internal electrogoniometers [4]. Various reviews have documented that the internal rotator (IR) musculature is stronger in swimmers as a result of the repetitive concentric contractions required during the propulsive period of the swim stroke. Conversely, external rotator (ER) strength is reliably weaker in swimmers and high eccentric requests put on the external rotator muscles cause chronic fatigue, making it hard to control glenohumeral-joint translation and muscular imbalances in the shoulder rotators of youthful swimmers. As a result of increased levels of IR strength and endurance that are proportionally larger than those of their antagonists. A compensatory strength training program should be considered $[5,6]$.

Typical strength ratios for the ER and IR of the shoulder have accounted for to be $2: 3$ roughly $66 \%$ in ordinary. Keeping up a balance of quality between the external and internal rotators of the shoulder is basic for typical muscular force couple activity and, along these lines, fundamental for glenohumeral steadiness. Assessing the muscular strength balance of the internal and external rotators is of crucial significance when interpreting upper limb strength tests [7].

As indicated by Myers et al. [8] objective data with respect to the multifaceted balance of agonist-antagonist muscular quality encompassing the glenohumeral joint is a fundamental asset in the restoration and prophylactic treatment of the shoulder joint. Anomalous external to internal rotator torque proportion is an unavoidable outcome of swimming. Therefore, the key figure preparing programs proposed to improve shoulder ER muscle quality in overhead competitors is the adjustment in ER to IR quality proportion particularly to begin swimmers to limit the danger of future damage [9].

In spite of advances in restoration and surgical methods, the best "treatment" remains counteractive action. So as to fulfill this, coaches and swimmers need to get comfortable with pro-per training methods, mechanics and have the capacity to perceive the normal changes in stroke mechanics designs related with shoulder dysfunction. With a specific end goal to diminish the risk of swimmer's shoulder, an injury prevention program must address strength imbalances and impeded range of motion to lessen the danger of shoulder impingement [10]. Isokinetic strength assessment of shoulder rotation is a profitable method in shoulder injury appraisal, especially aggravations in the agonist-antagonist balance. It is a reference technique for assessing shoulder muscle quality and distinguishing shortfalls in particular muscle groups found in certain shoulder disorders. Such measurement is a profitable apparatus for situating rehabilitation towards the affected muscle groups [11]. Isokinetic resistance training is powerful in improving muscular strength coming about because of high strengths delivered by muscles contracting at a consistent speed through the whole scope of joint movement. Isokinetic activities might be performed concentrically or eccentrically as external forces are applied to the limb [12].

Plyometric activities defined as eccentric loading instantly took after by a concentric contraction. Plyometric practice alludes to those exercises that empower a muscle to achieve maximal drive in the most limited conceivable time. A plyometric action is isolated into three 
stages including, the eccentric preload stage, the amortization stage and the concentric contraction. Arrangement of the three stages identified as the stretch shortening cycle [13]. Plyometric exercises considered as a vital segment of rehabilitation, which underpins the hypothetical ideas for utilizing these sorts of exercises for the upper limbs. This kind of practice performed for shoulder strength training. However, on account of the different levels of force related with plyometrics, and additionally the critical impacts these activities have on proprioception and muscle execution, it is sensible that plyometrics could likewise be advantageous if actualized in the before phases of shoulder restoration[14].

Therefore, the purpose of this study was to compare the outcomes of isokinetic training and plyometric training in terms of: 1) shoulder proprioceptive sense 2) shoulder external to internal rotators strength ratio (ER concentric/ IR concentric ratio).

\section{MATERIALS AND METHODS}

Subjects: A preliminary power analysis applied with effect size $=0.40, \alpha=0.05$, power $=0.80$, groups $=3$ and evaluation times $=2$ with a result of sample size of total 66 children at least for this study.

Through the following procedure, eighty swimmer children assessed for eligibility of this study recruited from Wadi Degla Sporting Club. Three children did not meet the inclusion criteria while another two refused to engage in this study. The study conducted on seventy-five swimmer boys, their age ranged from 13-15 years. Each child assessed after 24-48 hours from the last training to minimize the difference of training load either over training or unloading of muscles. Moreover, all participants belonged to the same swimming team, which is engaged in a 4 hours of training per week. All children submitted to a complete medical examination prior to the beginning of the study. Children who met the following inclusion criteria enrolled in the current study. They had good style swimming and free from rheumatoid arthritis or other inflammatory joint diseases. Accordingly, participants excluded from the study if they had suffered a recent shoulder, cervical or thoracic injury for which they have sought medical attention and/or had kept them from practicing. In addition, any child skipped three successive times from the exercise program excluded from the study. The recruitment process and the flow chart of participants illustrated in figure 1. Demographic characteristics of participants presented in Table 1.

Instructions about the purpose and methods of testing provided for each child before each testing session to make every child familiar with the device. All children's parents gave their informed consent to have their children participated in the study. The work carried out in accordance with the code of Ethics of the World Medical Association (Declaration of Helsinki) for experiments involving humans. The study approved by the Ethics Review Committee of Faculty of Physical Therapy, Cairo University, Egypt (P.T.REC/012/ 001583).

Randomization: Following the baseline measurements, randomization performed simply by adding a specific identification number for each child. Consequently, the recruited children allocated randomly on a computerized base using Statistical Package for the Social Sciences (SPSS) into three equal groups of 25 children each. These three groups named as control group (A) continued to participate in regularly scheduled swim practice. Study group (B) received shoulder isokinetic training as well as regularly scheduled swim practice similar to group A. Study group (C) received shoulder plyometric training in addition to regularly scheduled swim practice given to group $A$.

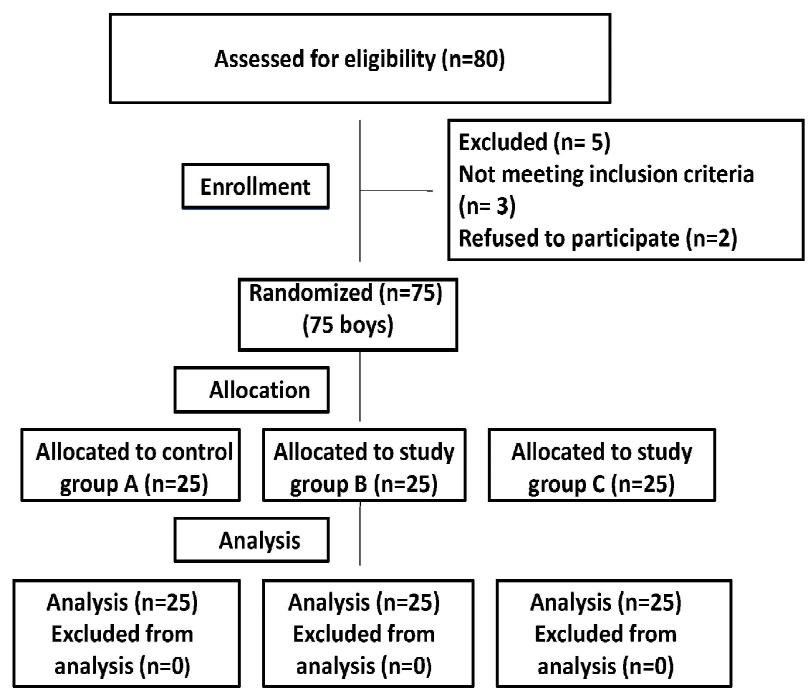

Fig. 1: Flow chart of the study. 
Active joint repositioning sense and ER concentric /IR concentric strength ratio of the dominant shoulder assessed for each child of the three groups before and after 8 weeks of training program by using the Biodex III isokinetic dynamometer.

\section{Instrumentations}

For evaluation: Biodex III isokinetic dynamometer (Biodex Medical System, Inc, Shirley, NY, USA) is one of the most comprehensive computer devices provided with attachments and isolation straps for every part of the body. It provides testing data, graph recording and printed results for torque, work, power and proprioception [15].

\section{For treatment}

Biodex III isokinetic dynamometer: It utilized for the training of different muscle groups so as to enhance the muscular performance in dynamic conditions and consistent preselected speed of movement. These elements give safety in the recovery of patients with muscular and ligamentous injuries. The movement speed of various exercises recreated during training to enhance the training impact. Data acquisition and analysis improved by utilizing computer systems interfaced to isokinetic dynamometers [16].

The equipments utilized in plyometric training included medicine balls ( $1 \mathrm{~kg}$ for the single arm exercises and $1.36 \mathrm{~kg}$ for the 2 -handed exercises) and Theraband latex tubing (The Hygenic Corp., Akron, $\mathrm{OH}$ ).

\section{Procedures for evaluation}

Active repositioning test procedure: Active joint reposition senses determined by measuring the subject ability to actively reproduce a passively placed joint position. Active repositioning accuracy test of dominant shoulder was measured by Biodex III Isokinetic Dynamometer. Dominant arm dictated by asking swimmers which arm they would use to write. All participated children were right handed. Each child positioned sitting on the related seat and secured with belts around the trunk and pelvis so as to avoid compensatory movements with his shoulder situated in $90^{\circ}$ of shoulder abduction, $90^{\circ}$ of elbow flexion, and neutral pronation /supination [17].
The lever arm attachment length and seat back adjusted so that the rotational axis of the dynamometer situated to be co-axial with the shoulder axis during the testing procedures. The forearm secured to the lever arm, constraining shoulder movement to internal and external rotation. The positioning of the subjects and the joint alignment done by the directions set out in the device's operations manual [18].

Preceding being tested, each child received a practice session followed by a 30-second rest period, and subsequently began the active reposition test. Three positions tested according to Blasier et al. [19] The reference angles were $45^{\circ}$ of internal rotation (from $90^{\circ}$ at the start to the $45^{\circ}$ internal position), $45^{\circ}$ of external rotation (from $90^{\circ}$ at the start to the $45^{\circ}$ external position), and $75^{\circ}$ of external rotation (from $30^{\circ}$ at the start to the $75^{\circ}$ external position). During the test session for the active reposition test, all children were blindfolded in an effort to eliminate the commitment of visual cues to joint repositioning [4]. Participants asked to focus on the presented angle and actively move their shoulder to each of the pre-chosen test positions within $60 \mathrm{sec}$.

The angular speed for the active reposition test set at $30 \% \mathrm{sec}$. Three trials recorded for every reference angle, each starting from the starting position/angle. There was a period of rest, one minute between each trial and the other. Joint reposition sense assessments recorded in absolute degrees of error between the preselected angle and the repositioned angle [20]. The mean angular differences of the three trials recorded and utilized in the statistical analysis.

Isokinetic testing procedure: Biodex III Isokinetic Dynamometer used to determine isokinetic peak torque values for concentric ER/ IR strength ratio of the dominant shoulder. From the previous described position, range of motion set from $0^{\circ}-90^{\circ} \mathrm{ER} / \mathrm{IR}$ rotation of the shoulder joint. Concentric strength testing measured at angular velocities of 60 , and $180 \%$ $\mathrm{s}$. The same sequence followed for all the subjects to increase reliability of data acquisition. Before data collection, all subjects in the three groups completed a 5 minute warm up on an upper body ergometer before starting their 
testing or training protocol [21].

The testing protocol consisted of three submaximal warm up repetitions at each angular velocity to be familiar with the isokinetic exercise. A two minute rest provided at the end of the practice session. Five maximal concentric test repetitions completed through the range of motion from $0^{\circ}$ to $90^{\circ}$ at each angular velocity [22]. Children instructed to provide maximal effort throughout the entire repetition and given both verbal and visual feedback and encouragement to facilitate maximum performance. One minute rest period allowed between tests of each velocity. At the end of testing, ER/IR peak torque ratio ascertained.

\section{Procedures for treatment}

Isokinetic training program: The isokinetic group followed an isokinetic strengthening program utilizing the isokinetic testing position depicted previously. The training protocol comprised of 8 weeks of isokinetic exercise workouts, two times each week. Every individual workout consisted of ten sets of ten repetitions using the velocity spectrum $90,120,180,210$, $240,240,210,180,120$, and $90 \%$ s. A velocity spectrum rehabilitation protocol used to enhance a training response at various angular velocities. Ten repetitions at each angular velocity with 10 -second rest between angular velocities were optimal to increase isokinetic peak torque across a velocity spectrum [23]. A total of 16 workout sessions were completed by every child in the allotted 8 weeks period.

Plyometric training protocol: The training protocol comprised of 8 weeks of plyometric training, two sessions per week. Children instructed to utilize maximal exertion and to perform exercises in a ballistic manner depicted by Pretz [24] in order to decrease the amortization phase and to boost the training effects. A thorough warm-up is essential prior to plyometric training in the form of general mobility, particularly about the joints involved in the arranged plyometric session. A cool-down should follow each session. Exercises performed using 3 sets of 10-20 repetitions. The progression of the training protocol was $1^{\text {st }}$ and $2^{\text {nd }}$ week the participants completed 3 sets of 10 repetitions, from $3^{\text {rd }}$ to $5^{\text {th }}$ week they completed 3 sets of 15 repetitions and finally from $6^{\text {th }}$ to $8^{\text {th }}$ week 3 sets Int J Physiother Res 2017;5(3):2133-43. I ISSN 2321-1822 of 20 repetitions were completed [25] with 90 seconds of rest between each set for rebuilding of muscles stored energy [26].

According to Carter et al. [25] and Davies et al. [27], plyometric training program includes wall dribbling exercises, plyometric ball throws and Theraband exercises focused on strengthening the external rotators of the shoulder.

The plyometric training program includes the following exercises:

Plyometric push-ups against wall each child instructed to stand against wall leaning towards wall then pushing his body away from the wall.

Plyometric push-ups on the ground each child started by getting into a push-up position on the ground lowering himself to the ground and then explosively pushing up so that his hands leave the ground. Each child instructed to catch his fall with his hands and immediately lower himself into push-up again.

Theraband 90/90 external rotation of shoulder each child should start this exercise with his shoulder abducted $90^{\circ}$ and elbow flexed $90^{\circ}$. Theraband taut and positioned to oppose the external rotators of the shoulder.

Theraband external rotation of shoulder each child instructed to perform the same previous exercise, but from adducted shoulder with his trunk facing sideways throughout the exercise as he tucks his elbow into his side.

Two hands chest pass with plyometric ball each child instructed to stand holding plyometric ball throwing it forward pushing it off his chest. He should try to anticipate the catch and return the ball as quickly as possible keeping the catch time as short as possible.

Slams with plyometric ball from standing position, each child instructed to pull plyometric ball back overhead and forcefully throw ball down on the ground as hard as possible. The child then catches the ball on the bounce from the ground and repeat.

Overhead throws each child instructed to perform the same previous exercise, but he forcefully throws the ball forward as far as possible into the wall. The child then catches the ball on the bounce from the wall and repeat.

Single arm overhead throws from standing 
position, the child instructed to grasp plyometric ball and throw the ball up into the air as high as possible then catches the ball on the bounce and repeat.

Side throws with plyometric ball the child instructed to hold plyometric ball with both hands with arms slightly bent. He swings the ball over to right and/or left hip and forcefully underhand toss ball towards the wall, and then he catches the ball on the bounce from the wall and repeat.

$\mathbf{9 0 / 9 0}$ external rotation side throw with plyometric ball the same as previous exercise, but one hand side arm throw with ball from $90^{\circ}$ shoulder abduction and $90^{\circ}$ elbow flexion.

Plyometric arch chops the child instructed to raise the plyometric ball up with his arms extended over his right shoulder. In one continuous motion he brings the ball down towards his left foot. He stands back up and raises the ball straight up over his left shoulder and then brings the ball down towards his right foot. Return to the starting position and repeat.

Catch and throw backhand from standing position the participant instructed to bend his elbow to 90 degrees and tucks his elbow into his side. The child rotates his arm out to catch the plyometric ball. The child throws the ball back to the therapist and focuses the effort on external rotators.

Reverse catch external rotation plyometric The same as previous exercise while the arm in $90^{\circ}$ of abduction and $90^{\circ}$ of elbow flexion.

Prone $\mathbf{9 0 / 9 0}$ external rotation plyometric The child positioned prone on a standard treatment table with $90^{\circ}$ of shoulder abduction and $90^{\circ}$ of elbow flexion. The plyometric ball used to alternately catch and drop.

Control group participated only in regular swimming training practice. Three groups swam for four hours per week in the eight weeks throughout the study. The swimming training was identical for the three groups and conducted by the same coach to ensure consistency in coaching techniques and programming [28].

Statistical analysis: Descriptive statistics of mean and standard deviation calculated for all measured variables. Parametric tests (paired t-test and ANOVA) used to analyze the pre and post treatment mean values of shoulder prop- rioception within group and among groups. Nonparametric tests (Wilcoxon-Signed Rank, Kruskal-Wallis and Mann-Whitney Signed Rank) used to analyze the pre- and post-treatment mean values of ER/IR concentric ratio within group and among groups. Statistical analysis performed using the software package SPSS for Windows, version 20. A p-value of less than 0.05 considered significant $(95 \% \mathrm{Cl})$.

\section{RESULT}

There were no significant differences among the three groups with respect to demographic characteristics as shown in Table 1 as well as in the baseline mean values of active repositioning senses and ER/IR concentric strength ratios at two angular velocity $60 \%, 180 \% \mathrm{~s}$ as shown in Table 2.

Tables 2 and 3 show the results of within group comparison as there were significant reductions in absolute degrees of error at $45^{\circ} \mathrm{IR}, 45^{\circ} \mathrm{ER}$ and $75^{\circ} \mathrm{ER}$ as well as ER/ IR concentric ratios at $60 \%, 180 \%$ post treatment in isokinetic training and plyometric training groups with non-significant changes in the control group as compared with baseline values. In addition, table 2 and 3 summarize the results of among group's comparisons of proprioception and ER/ IR concentric ratios for the three groups. There were significant differences among the three groups regarding the measured variables after treatment.

Table 1: Demographic characteristics of participated children.

\begin{tabular}{|l|c|c|c|c|}
\hline & Control group & Isokinetic group & Plyometric group & p-value \\
\hline Age (years) & $14.12 \pm 0.78$ & $13.96 \pm 0.84$ & $13.84 \pm 0.74$ & 0.45 \\
\hline Weight $(\mathrm{kg})$ & $43.20 \pm 2.04$ & $44.36 \pm 2.73$ & $44.28 \pm 3.57$ & 0.28 \\
\hline Height $(\mathrm{cm})$ & $146.68 \pm 3.77$ & $148.00 \pm 4.09$ & $147.96 \pm 2.90$ & 0.34 \\
\hline BMI $\left(\mathrm{kg} / \mathrm{m}^{2}\right)$ & $20.10 \pm 1.13$ & $20.25 \pm 1.03$ & $20.24 \pm 1.82$ & 0.9 \\
\hline
\end{tabular}

Values are mean \pm SD; BMI: Body Mass Index; $p$-value: Level of significance $* p<0.05$

It is evident from Table 4, that there were significant differences between groups in all measured variables when multiple comparisons performed after eight weeks of treatment ( $p$ $<0.05$ ). There were significant differences in all measured variables between control group $A$ and isokinetic group B in favor of group B. Comparison between group $A$ and plyometric group $C$ revealed significant differences in all measured 
variables in favor of group $C$. Moreover, comparison between group $B$ and $C$ showed significant differences in ER/ IR concentric ratios at both angular velocities in favor of group $B$ while non significant differences observed between both groups in shoulder proprioception.

Table 2: Comparison of the mean values of joint position sense within and among groups.

\begin{tabular}{|c|c|c|c|c|c|c|c|c|c|c|c|c|}
\hline & \multicolumn{2}{|c|}{ JPS $45^{\circ}$ IR } & \multirow{3}{*}{$\mathrm{t}$-value } & \multirow{3}{*}{$p$-value } & \multicolumn{2}{|c|}{ JPS $45^{\circ}$ ER } & \multirow{3}{*}{$t$-value } & \multirow{3}{*}{$p$-value } & \multicolumn{2}{|c|}{ JPS $75^{\circ}$ ER } & \multirow{3}{*}{$\mathrm{t}$-value } & \multirow{3}{*}{$p$-value } \\
\hline & Pre & Post & & & Pre & Post & & & Pre & Post & & \\
\hline & $\bar{X} \pm S D$ & $\bar{X} \pm S D$ & & & $\bar{X} \pm S D$ & $\bar{X} \pm S D$ & & & $\bar{X} \pm S D$ & $\bar{X} \pm S D$ & & \\
\hline Control group & $3.1 \pm 0.27$ & $3.04 \pm 0.22$ & 1.66 & 0.109 & $3.92 \pm 0.31$ & $3.87 \pm 0.32$ & 0.91 & 0.37 & $3.25 \pm 0.31$ & $3.26 \pm 0.28$ & 0.3 & 0.76 \\
\hline Isokinetic group & $3.16 \pm 0.31$ & $1.91 \pm 0.38$ & 12.86 & $0.0001^{*}$ & $4.08 \pm 0.24$ & $2.64 \pm 0.55$ & 19.84 & $0.0001^{*}$ & $3.2 \pm 0.27$ & $1.77 \pm 0.22$ & 38.86 & $0.0001^{*}$ \\
\hline Plyometric group & $3.25 \pm 0.34$ & $2.04 \pm 0.33$ & 21.64 & $0.0001^{*}$ & $4.01 \pm 0.19$ & $2.69 \pm 0.53$ & 16.16 & $0.0001^{*}$ & $3.21 \pm 0.27$ & $1.7 \pm 0.34$ & 34 & $0.0001^{*}$ \\
\hline F-value & 1.5 & 93.13 & & & 2.238 & 51.91 & & & 0.216 & 239.06 & & \\
\hline $\mathrm{p}$-value & 0.22 & $0.0001^{*}$ & & & 0.114 & $0.0001^{*}$ & & & 0.805 & $0.0001^{*}$ & & \\
\hline
\end{tabular}

$\overline{\mathrm{X}}$ : Mean; SD: Standard deviation; t- value: Paired t -test; F- value: Analysis of variance value; JPS: Joint position sense; $p$ - value: Level of significance $* p<0.05(95 \% \mathrm{Cl})$

Table 3: Comparison of the mean values of external to internal rotators concentric ratios within and among groups.

\begin{tabular}{|c|c|c|c|c|c|c|c|c|}
\hline & \multicolumn{2}{|c|}{ ER/IR concentric ratios at $60^{\circ} / \mathrm{s}$} & \multirow{3}{*}{ Z-value } & \multirow{3}{*}{$p$-value } & \multicolumn{2}{|c|}{$\mathrm{ER} / \mathrm{IR}$ concentric ratios at $180^{\circ} / \mathrm{s}$} & \multirow{3}{*}{ Z-value } & \multirow{3}{*}{$p$-value } \\
\hline & Pre & Post & & & Pre & Post & & \\
\hline & $\bar{X} \pm S D$ & $\bar{X} \pm S D$ & & & $\bar{X} \pm S D$ & $\bar{X} \pm S D$ & & \\
\hline Control group & $74.96 \pm 2.90$ & $74.64 \pm 2.17$ & -0.397 & 0.691 & $76.04 \pm 2.55$ & $75.72 \pm 3.07$ & -0.471 & 0.638 \\
\hline Isokinetic group & $75.68 \pm 1.67$ & $66.12 \pm 2.18$ & -4.419 & $0.0001^{*}$ & $76.44 \pm 3.37$ & $67.16 \pm 2.56$ & -4.293 & $0.0001^{*}$ \\
\hline Plyometric group & $75.16 \pm 2.82$ & $68.12 \pm 2.14$ & -4.208 & $0.0001^{*}$ & $76.24 \pm 3.08$ & $69.36 \pm 2.54$ & -4.25 & $0.0001^{*}$ \\
\hline K-value & 1.205 & 52.63 & & & 0.286 & 48.04 & & \\
\hline$\overline{p-v a l u e}$ & 0.548 & $0.0001^{*}$ & & & 0.867 & $0.0001^{*}$ & & \\
\hline
\end{tabular}

$\overline{\mathrm{X}}$ : Mean; SD: Standard deviation; Z: Wilcoxon signed-rank test value; K- value: Kruskal-Wallis test value; ER/IR: External/ Internal rotators; $\mathrm{p}$-value: Level of significance * $\mathrm{p}<0.05(95 \% \mathrm{Cl})$

Table 4: Comparison of post-treatment mean values of joint position sense and external to internal rotators concentric ratios between groups.

\begin{tabular}{|c|c|c|c|c|c|c|c|c|c|c|}
\hline & \multicolumn{2}{|c|}{ JPS $45^{\circ}$ IR } & \multicolumn{2}{c|}{ JPS $45^{\circ}$ ER } & \multicolumn{2}{c|}{ JPS $75^{\circ}$ ER } & \multicolumn{2}{c|}{ ER/IR ratios at $60^{\circ} / \mathrm{s}$} & \multicolumn{2}{c|}{ ER/IR ratios at $180^{\circ} / \mathrm{s}$} \\
\cline { 2 - 12 } & MD & $\mathrm{p}$ - value & MD & $\mathrm{p}$ - value & MD & p-value & MD & p-value & MD & $p$ - value \\
\hline $\begin{array}{c}\text { Control group vs } \\
\text { isokinetic group }\end{array}$ & 1.12 & $0.000^{\mathrm{a}}$ & 1.23 & $0.000^{\mathrm{a}}$ & 1.49 & $0.000^{\mathrm{a}}$ & 8.52 & $0.000^{\mathrm{b}}$ & 8.56 & $0.000^{\mathrm{b}}$ \\
\hline $\begin{array}{c}\text { Control group vs } \\
\text { plyometric group }\end{array}$ & 1 & $0.000^{\mathrm{a}}$ & 1.17 & $0.000^{\mathrm{a}}$ & 1.56 & $0.000^{\mathrm{a}}$ & 6.52 & $0.000^{\mathrm{b}}$ & 6.36 & $0.000^{\mathrm{b}}$ \\
\hline $\begin{array}{c}\text { Isokinetic group vs } \\
\text { plyometric group }\end{array}$ & 0.12 & 0.176 & 0.05 & 0.683 & 0.07 & 0.376 & 2 & $0.002^{\mathrm{b}}$ & 2.2 & $0.002^{\mathrm{b}}$ \\
\hline
\end{tabular}

MD: Mean difference; JPS: Joint position sense; ER/IR: External/ Internal rotators; a: Significant difference between both groups (post hoc least significant difference test); b: Significant difference between both groups (MannWhitney signed-rank test); $p$-value: Level of significance $p<0.05(95 \% \mathrm{Cl})$

\section{DISCUSSION}

Rehabilitation programs incorporate activities to reestablish muscle imbalances and sensorimotor control are essential for patients with shoulder injuries [29]. The aim of this study was to investigate the impact of two types of shoulder exercise training programs over 8-weeks period on active reproduction joint position sense and $E R / I R$ strength ratio in swimmer children.
Selection of the high intensity of both training programs comes in agreement with Lin and Karduna [30] who stated that activities, particularly focusing on individual muscles with low intensity may not be adequate to enhance a shoulder joint position sense. Future work expected to additionally investigate which types of exercise are more effective in enhancing the 
joint position sense and the mechanisms associated with those progressions.

In the current study the pre treatment mean values of the measured variables showed that the swimmer groups have a more prominent muscle imbalance of the shoulder joint and, consequently, higher risk for injury. This comes in agreement with West et al. [31] who reported that decrease in the value of concentric strength of the ER, consolidated with an increase of the strength of the IR is a feature of athletes who present with instability of the glenohumeral joint contributing to an increased risk for joint injury. Accordingly, this fact reinforces the significance of performing particular compensatory exercises, which should concentrate mainly on the ER.

Selection of the reference angles in JPS comes in consistent with Blasier et al. [19] who distinguished larger deficiencies in angular reproduction in the middle range of rotation (at a set angle of $30^{\circ}$ ) than that at other set angles less than $30^{\circ}$. In this study, the reference angles $45^{\circ}$ and $75^{\circ}$ in the middle ranges of internal and external rotations were set in active JPS test. The larger angular changes can detect specified mechanoreceptors more precisely.

The findings of this study support the use of both upper extremity isokinetic and plyometric strength training for reducing commonly identified upper extremity injury risk factors and improving upper extremity performance. The primary findings of the current study demonstrated that plyometric and isokinetic groups had significantly improved JPS from pretests to posttests as well as ER/IR concentric strength ratio when compared with the control group. The exercise groups were better able to reproduce angles and had a better awareness of the location of their upper extremity in space in comparison with the control group. Moreover, isokinetic group showed the greatest improvements in agonist antagonist ratio when compared with control and plyometric groups.

In the current study strength-ratio values at baseline were already close to $76 \%$ optimal values. Furthermore, these values reached $66 \%$ to $68 \%$ following treatment program. This indicates that both training programs allowed the shoulder rotator muscles to remain balanced. Int J Physiother Res 2017;5(3):2133-43. I ISSN 2321-1822
This comes in agreement with Hurd et al. [32] who reported that a proper balance between IR and ER musculature thought to provide dynamic stabilization to the inherently unstable shoulder joint.

In the present study, isokinetic muscular training has a distinct advantage over other method of strength training as maximal torque can be created throughout the entire range of motion. Improvement of ER/IR strength ratio in the isokinetic group could clarify by the work of Wernbom et al. [33] who reported that in isokinetic training, muscle activities performed at a constant angular velocity. This feature gives safety in the rehabilitation of patients with muscular and ligamentous injuries. Since the subject can freely differ the level of exertion in the whole movement to accommodate for pain or weakness in certain regions of the range of motion. The isokinetic mode is very helpful in restoration and enhances the muscular performance in dynamic conditions.

This finding supported by the work of Baltzopoulos and Brodie [34] who exhibited that isokinetic training has a predominant impact upon different modes of training for swimming performance. This recommends isokinetic training resembling the functional activity of the sport can effectively enhance muscular force development. Furthermore, Beneka et al. [35] distinguished more prominent changes in muscle performance after isokinetic strengthening. They compared the effectiveness of different training modes in altering shoulder strength ratios. They concluded that isokinetic strengthening is the best strategy for changing strength proportions of the rotator cuff muscles.

With respect to this study, using isokinetic training considered more compelling in enhancing $E R / I R$ ratio. This finding highlights the significance of the principle of contraction specificity during isokinetic training. This principle based on research supporting the concept that resistance training impacts are most robust when performed at the velocity in which the actual activity happens [36] Comparing the mean ratio of the two angular velocities tested, it seems that, at greater velocity the ratios are somewhat increased. This outcome is in accordance with Hinton [37] who reported that the proportions 
rise as the angular velocity increments. Conversely, Ivey et al. [38] found that the ratios diminished with faster velocities.

The mechanism for the improvement of shoulder joint reposition sense in both isokinetic and plyometric groups is most likely related to the extra stimulation of the joint and muscle receptors realized by the resistance exercise. In this manner, the physiologic reason behind the enhanced performance is that the proprioceptive spindles became more delicate after strength training, bringing about better position detection. Receptors in charge of detecting joint position include the Pacinian corpuscles and Ruffini end-organs found in the joint capsule and the Golgi tendon organs and muscle spindles found in the muscle. Consequently, all these receptors are delicate to changes in tension within the muscle or noncontractile tissues [39]. Moreover, strengthening exercises of rotator cuff and scapulothoracic muscles categorized as open-chain and closed-chain exercises and are typically part of the shoulder proprioception rehabilitation protocol [40].

In the present study, improvement of proprioceptive acuity in both training group may attribute to the impact of training intensity which comes in agreement with Salles et al. [41] who demonstrated that the group trained with higher intensity showed more improvement, compared to the group trained with lower intensity. Considering the results of the present study, open-chain exercise involving multiple joints and large muscle groups with high intensity might be more effective in enhancing JPS.

Specifically, the control group maintained the same absolute degrees of error and did not improve proprioceptive acuity. Therefore, the findings of this study support the current clinical practice of strength training to address proprioception shortages in JPS. Accordingly,strengthtraining activities used to increase muscular development and enhance proprioception and neuromuscular control [4].

The findings of this study support the use of plyometric training for improving kinesthetic awareness and agonist antagonist strength ratio, which could credit to the impact of plyometric training on peripheral adaptations that may result from the repetitive stimulation of the articular mechanoreceptors close to the end scope of movement in the shoulder during these exercises. Moreover, rapid length/tension changes put on the tendomuscular structures during eccentric loading may have encouraged adjustments to muscle spindles and Golgi tendon organs. Heightening the sensitivity of the muscle spindle system may increase their afferent contributions to the central nervous system with respect to joint position. These adaptations may likewise be responsible for the improved proprioception [42].

Central adaptations resulting from plyometric training may also improve proprioception. The novelty of this task required preliminary muscle activation in anticipation of catching the ball and involuntary muscle activity for concentric force production while throwing the ball. Joint position sense essentially enhanced when muscles stimulated; hence, this activity may have reinforced or enhanced conscious awareness of joint position. Consequently, incorporating these activities into upper extremity rehabilitation can help with restoring proprioception and neuromuscular control through peripheral and/or central adaptations [43].

The findings in this study revealed that external to internal strength ratio decreased after 8 weeks of functional training as a result of improvements in the external rotation mean peak torque values. For this reason, exceptional accentuation sets on strengthening the external rotators in young swimmers. Upper extremity sports require a most extreme amount of muscle force delivered in a minimal amount of time. These specific demands can successfully reproduced by performing shoulder plyometric exercises, and if a diminishing in amortization time enhances involuntary muscle activity, it will allow for greater muscle recruitment and usage of stored elastic energy. Increased neuromuscular proficiency and coordinated muscle firing may diminish the onset of exhaustion and help with dynamic restraint and functional stability [14].

The plyometric group's improvement in torque decrement may attribute to the relatively high repetitions performed during training that increased muscle coordination and productivity, resulting in the maintenance of torque production 
during prolonged episodes of exercise.

Plyometric exercises promote endurance adaptations in the shoulder rotator cuff musculature, which is basic for reestablishing functional stability. Consequently, utilized appropriately, plyometric-ball, and Theraband activities can effectively accomplish sport-specific strength and capacity of the musculature around the shoulder [44].

The results of this study support the rationale that plyometric training may not be the most effective activity to improve torque advancement, especially in highly trained competitors. Also, in light of the fact that plyometric exercises performed at different levels of intensity, it is suitable to utilize them in conjunction with strengthening exercises [45].

The results of this study contradict with Heiderscheit et al. [46] who stated that neither isokinetic group, nor plyometric group showed significant changes in the kinesthetic awareness of the shoulder. Furthermore, they found that plyometric training was not effective for increasing power output while isokinetic training improves power output.

\section{CONCLUSION}

From the obtained results, it concluded that athletes who particularly use the shoulder to perform their sport can help them be more proficient and limit the risk of injury by applying simple strength training protocols. Both exercise training programs studied were successful in modifying the joint position sense and the strength ratios, but isokinetic training appeared to be significantly more effective. If isokinetic equipment is not accessible, plyometric training is a practical alternative to adjust shoulder rotator strength ratio to reestablish any muscle imbalances and to enhance kinesthetic awareness.

\section{ACKNOWLEDGEMENTS}

The authors would like to express their appreciation to all the children and their parents for their co-operation and participation in this study.

\section{Conflicts of interest: None}

Source of Funding: This research received no specific grants from any funding organization in the public, commercial, or non- profit sectors.

\section{REFERENCES}

[1]. Heinlein SA, Cosgarea AJ. Biomechanical considerations in the competitive swimmer's shoulder. Sports Health 2010; 2(6): 519-525.

[2]. Hibberd EE, Myers JB. Practice habits and attitudes and behaviors concerning shoulder pain in high school competitive club swimmers. Clin J Sport Med 2013; 23(6):450-455.

[3]. Fyhr C, Gustavsson L, Wassinger C, Sole G. The effects of shoulder injury on kinaesthesia: A systematic review and meta-analysis. Manual Ther 2015; 20: 28-37.

[4]. Dover G, Powers ME. Reliability of joint position sense and force production measures during internal and external rotation of the shoulder. J Athl Train 2003; 38(4):304-310.

[5]. Batalha NM, Raimundo AM, Carus P, Barbosa TM, Silva AJ. Shoulder rotator cuff balance, strength, and endurance in young swimmers during a competitive season. J Strength Cond Res 2013; 27(9): 2562-68.

[6]. Bea JS, Benson J. The Effects of a 6-Week Dry Land Exercise Program for High School Swimmers. J Phys Edu Sports Manage 2015; 2(1):1-17.

[7]. Ellenbecker TS, Davies GJ. The application of isokinetics in testing and rehabilitation of shoulder complex. J Athl Train 2000; 35(3):338-350.

[8]. Myers JB, Laudner KG, Pasquale MR, Bradley JP, Lephart SM. Scapular Position and Orientation in throwing athletes. Am J Sports Med 2005; 33:263271.

[9]. Astrab J, Small E, Kerner MS. Muscle strength and flexibility in young elite swimmers. J Med Sci Sports Exerc 2001; 33(5):534.

[10]. Hibberd EE, Oyama S, Spang JT, Prentice W, Myers JB. Effect of a 6- week strengthening program on shoulder and scapular-stabilizer strength and scapular kinematics in division I collegiate swimmers. J Sport Rehabil 2012; 21(3):253.

[11]. Edouarda P, Codinec P, Samozinob P, Bernarde PL, Hérissond C, Gremeaux V. Reliability of shoulder rotators isokinetic strength imbalance measured using the Biodex dynamometer. J Sci Med Sport 2013; 16(1):162-165.

[12]. Richardson SM, Miller LE, Wootten DF, Ramp WK, Herbert WG. Concentric and eccentric isokinetic resistance training similarly increases muscular strength, fat-free soft tissue mass, and specific bone mineral measurements in young women, Osteoporos Int 2007; 18:789-96

[13]. Chimera NJ, Swanik KA, Swanik CB, Straub SJ. Effects of plyometric training on muscle activation strategies and performance in female atheletes. J Athl Train 2004; 39(1):24-31

[14]. Swanik KA, Lephart SM, Swanik CB, Lephart SP, Stone $\mathrm{DA}, \mathrm{Fu} \mathrm{FH}$. The effects of shoulder plyometric training on proprioception and selected muscle performance characteristics. J Shoulder Elbow Surg 2002; 11(6):579-86. 
[15]. Drouin J, Mcleod T, Shultz S, Gansneder B and Perrin D. Reliability and validity of the Biodex system 3 pro isokinetic dynamometer velocity, torque and position measurements. Eur J Appl Physiol 2004; 91(I):22-29.

[16]. Baltzopoulos V D, Brodie DA Isokinetic dynamometry. Applications and limitations. Sports Med 1989 Aug; 8(2):101-16.

[17]. Batalha NM, Raimundo AM, Carus PT, Fernandes OJ, Marinho DA, Martins AJ. Shoulder rotator isokinetic strength profile in young swimmers. Rev Bras Cineantropom Desempenho Hum 2012; 14(5):545-553.

[18]. Wilk K. Isokinetic testing - Setup and positioning. In Biodex System II Manual, Applications/Operations, Biodex System, Inc. New York, USA; 1991.

[19]. Blasier RB, Carpenter JE, Huston L. Shoulder proprioception effect on joint laxity, joint position, and direction of motion. Orthop Rev 1994; 1:45-50.

[20]. Lephart SM, Pincivero DM, Giraldo JL, Fu FH. The role of proprioception in the management and rehabilitation of athletic injuries. Am J Sports Med 1997; 25:130-7.

[21]. Ellenbecker TS, Mattalino AJ. Concentric isokinetic shoulder internal and external rotation strength in professional baseball pitchers. J Orthop Sports Phys Ther 1997; 25(5):323-328.

[22]. Davies GJ. A compendium of isokinetics in clinical usage. $4^{\text {th }}$ ed. Onalaska, Wisc: S \& S; 1992.

[23]. Malliou PC, Giannakopoulos K, Beneka AG, Gioftsidou A, Godolias G. Effective ways of restoring muscular imbalances of the rotator cuff muscle group: a comparative study of various training methods. Br J Sports Med 2004; 38:766-72.

[24]. Pretz R. "Ballistic Six" Plyometric training for the overhead- throwing athlete. Strength Cond J 2004; 26(6):62-66.

[25]. Carter AB, Kaminski TW, Douex JR, Knight CA, Richards JG. Effects of high volume upper extremity plyometric training on throwing velocity and functional strength ratios of the shoulder rotators in collegiate baseball players. J Strength Cond Res 2007; 21(1): 208-15.

[26]. Fortun CM, Davies GJ, Kernozck TW. The effects of plyometric training on the shoulder internal rotators. Phys Ther 1998; 78 (5):587.

[27]. Davies G, Riemann BL, Manske R. Current concepts of plyometric exercise. Int J Sports Phys Ther 2015; 10(6): 760-786

[28]. Potdevin FJ, Alberty ME, Chevutschi A, Pelayo P, Sidney MC. Effects of a 6-week plyometric training program on performances in pubescent swimmers. J Strength Cond Res 2011 Jan; 25(1):80-6.

[29]. Reinold MM, Escamilla RF, Wilk KE. Current concepts in the scientific and clinical rationale behind exercises for glenohumeral and scapulothoracic musculature. J Orthop Sports Phys Ther 2009; 39:105-117.

[30]. Lin YL, Karduna A. Exercises focusing on rotator cuff and scapular muscles do not improve shoulder joint position sense in healthy subjects. Hum Mov Sci 2016; 49:248-257.
[31]. West D, Sole G, Sullivan SJ. Shoulder external and internal rotation isokinetic strength in master's swimmers. J Sport Rehabil 2005; 14:12-19.

[32]. Hurd WJ, Kaplan KM, El Attrache NS, Jobe FW, Morrey $B F$, Kaufman KR. A profile of glenohumeral internal and external rotation motion in the uninjured high school baseball pitcher, part II: strength. J Athl Train 2011; 46:289-295.

[33]. Wernbom M, Augustsson J and Thomee R. The influence of frequency, intensity, volume and mode of strength training on whole muscle cross-sectional area in humans. Sports Med 2007; 37 (3): 225-264

[34]. Baltzopoulos V D, Brodie DA. The effect of isokinetic training on maximum torque output of swimmers, using the Akron Isokinetic Dynamometer. 5th International Symposium of Biomechanics in Sports, Athens, July 13-18, 1987.

[35]. Beneka A, Malliou P, Giannakopoulos K, et al. Different training modes for the rotator cuff muscle group. A comparative study. Isokinet Exerc Sci 2002; 10:73-9.

[36]. Ingebrigtsen J, Holtermann A, Roeleveld K. Effects of load and contraction velocity during three-week biceps curls training on isometric and isokinetic performance. J Strength Cond Res 2009; 23(6): 16701676.

[37]. Hinton RY. Isokinetic evaluation of shoulder rotational strength in high school baseball pitchers. Am J Sports Med 1988; 16:274-9.

[38]. Ivey FM, Calhoun JH, Rusche K, et al. Isokinetic testing of shoulder strength: normal values. Arch Phys Med Rehabil 1985; 66:384-6.

[39]. Röijezon U, Clark NC, Treleaven J. Proprioception in musculoskeletal rehabilitation. Part 1: Basic science and principles of assessment and clinical interventions. Manual Ther 2015; 20:368-377.

[40]. Rogol IM, Ernst G, Perrin DH. Open and closed kinetic chain exercises improve shoulder joint reposition sense equally in healthy subjects. J Athl Train 1998; 33: 315-20.

[41]. Salles JI, Velasques B, Cossich V, Nicoliche E, Ribeiro $\mathrm{P}$, Amaral MV, et al. Strength training and shoulder proprioception. J Athl Train 2015; 50: 277-280.

[42]. Voight ML. Stretch-strengthening: an introduction to plyometrics. Orthop Phys Ther Clin North Am 1992; 1:243-52.

[43]. Allegrucci M, Whitney SL, Lephart SM, Irrgang JJ, Fu $\mathrm{FH}$. Shoulder kinesthesia in healthy unilateral athletes participating in upper extremity sports. J Orthop Sports Phys Ther 1995; 21:220-6.

[44]. Beach ML, Whitney SL, Dickoff-Hoffman SA. Relationship of shoulder flexibility, strength and endurance to shoulder pain in competitive swimmers. J Orthop Sports Phys Ther 1992; 16: 362-8.

[45]. Sáez-Sáez de Villarreal E, Requena B, Newton RU. Does plyometric training improve strength performance? A meta-analysis. J Sci Med Sport 2010; 13: 513-522.

[46]. Heiderscheit BC, Mclean KP, Davies JG. The effects of isokinetic vs. plyometric training on the shoulder internal rotators. J Orthop Sports Phys Ther 1996; $23(2): 125-133$. 